\title{
Using satellites to investigate the sensitivity of longwave downward radiation to water vapor at high elevations
}

\author{
Catherine M. Naud, ${ }^{1}$ James R. Miller, ${ }^{2}$ and Chris Landry ${ }^{3}$ \\ Received 22 September 2011; revised 3 January 2012; accepted 4 January 2012; published 1 March 2012.
}

[1] Many studies suggest that high-elevation regions may be among the most sensitive to future climate change. However, in situ observations in these often remote locations are too sparse to determine the feedbacks responsible for enhanced warming rates. One of these feedbacks is associated with the sensitivity of longwave downward radiation (LDR) to changes in water vapor, with the sensitivity being particularly large in many high-elevation regions where the average water vapor is often low. We show that satellite retrievals from the Moderate Resolution Imaging Spectroradiometer (MODIS) and Clouds and the Earth's Radiant Energy System (CERES) can be used to expand the current ground-based observational database and that the monthly averaged clear-sky satellite estimates of humidity and LDR are in good agreement with the well-instrumented Center for Snow and Avalanche Studies ground-based site in the southwestern Colorado Rocky Mountains. The relationship between MODIS-retrieved precipitable water vapor and surface specific humidity across the contiguous United States was found to be similar to that previously found for the Alps. More important, we show that satellites capture the nonlinear relationship between LDR and water vapor and confirm that LDR is especially sensitive to changes in water vapor at high elevations in several midlatitude mountain ranges. Because the global population depends on adequate fresh water, much of which has its source in high mountains, it is critically important to understand how climate will change there. We demonstrate that satellites can be used to investigate these feedbacks in high-elevation regions where the coverage of surface-based observations is insufficient to do so.

Citation: Naud, C. M., J. R. Miller, and C. Landry (2012), Using satellites to investigate the sensitivity of longwave downward radiation to water vapor at high elevations, J. Geophys. Res., 117, D05101, doi:10.1029/2011JD016917.

\section{Introduction}

[2] Observations in high-elevation regions during the latter half of the 20th century suggest that they may be more sensitive than other regions to climate change [e.g., Diaz and Bradley, 1997; Liu and Chen, 2000; Rangwala et al., 2009]. In some mountains, minimum, maximum, or mean temperatures have warmed at a greater rate $\left(1^{\circ} \mathrm{C}-2^{\circ} \mathrm{C}\right.$ in the last century) than the global average [e.g., Diaz and Bradley, 1997; Beniston et al., 1997; Liu and Chen, 2000]. Moreover, within many mountain regions, an elevation dependence on surface warming is observed, with greater warming rates at higher altitudes [e.g., Beniston and Rebetez, 1996; Liu and Chen, 2000; Rangwala et al., 2009; Qin et al., 2009].

[3] Observations and modeling studies have suggested that increasing influences of snow and ice albedo feedback

\footnotetext{
${ }^{1}$ NASA GISS, Columbia University, New York, New York, USA.

${ }^{2}$ Marine and Coastal Sciences, Rutgers University, New Brunswick, New Jersey, USA.

${ }^{3}$ Center for Snow and Avalanche Studies, Silverton, Colorado, USA.

Copyright 2012 by the American Geophysical Union. 0148-0227/12/2011JD016917
}

mechanisms during spring and summer are important in causing an elevation-dependent warming in high-elevation regions [e.g., Giorgi et al., 1997; Chen et al., 2003; Rangwala et al., 2010]. However, clouds and water vapor are also potentially important in high-elevation feedback loops [e.g., Chen et al., 2003; Rangwala et al., 2009]. The longwave radiative effect caused by increases in atmospheric specific humidity during cold seasons was found to contribute to the rapid increase in the late 20th century surface warming across the Tibetan Plateau [Rangwala et al., 2009]. The midlatitude boundary layer, particularly at high elevations, is expected to be undersaturated in longwave absorption in the water vapor absorption lines [e.g., Ruckstuhl et al., 2007]. Therefore, an increase in surface water vapor content, especially during winter when the specific humidity is lowest, will cause a large increase in the longwave downward radiation (LDR) at the surface [Philipona et al., 2004].

[4] Despite numerous studies of high-elevation climate change, there are still major limitations in quantifying the processes responsible for these changes. Difficulties arise because of limited spatial and temporal resolution of data sets, interdependence among multiple climate variables, and 
a lack of observations for some important climate variables. One way to increase the number of observations is to incorporate satellite data into the analysis. Qin et al. [2009] found elevation-dependent warming in a wider portion of the Tibetan Plateau when they added satellite-derived surface temperatures to their surface observations.

[5] However, the impact of less accurate satellite observations over rugged snow-covered terrain on the evaluation of climate feedbacks needs to be assessed. For example, Yang et al. [2008] have found that computed surface longwave fluxes obtained by the International Satellite Cloud Climatology Program are much less accurate over regions of highly varying elevations such as the Himalayas. This is caused by larger uncertainties in temperature and humidity profiles that can affect the accuracy of surface flux computations [e.g., Zhang et al., 2006, 2007]. However, full assessments of satellite-derived quantities in highelevation areas are rare, mostly because "ground truth" is not available.

[6] In this paper we investigate whether satellite retrievals and computed surface fluxes can be used to quantify the magnitude of the longwave downward radiation-water vapor relationship in the water vapor feedback loop by comparing them with observations under clear-sky conditions at a well-instrumented site in the Rocky Mountains in southwestern Colorado. Since the mid-1990s, this region has experienced one of the largest increases in surface warming in the contiguous United States [e.g., Pepin and Losleben, 2002; Rangwala and Miller, 2010]. Because this region contributes significantly to the annual flow in major streams and rivers (e.g., Colorado and Rio Grande), it is paramount to isolate factors and mechanisms that can cause rapid warming there and in other high-elevation regions.

\section{Data and Method}

[7] Ground-based and satellite measurements were collected for the period 2005-2010. Cloudy situations were discarded, and the remaining data points were monthly averaged over the San Juan Mountains in southwestern Colorado. We use monthly means in order to reduce the variability caused by an imperfect cloud-clearing process, but we also tested our results with hourly coincident data.

[8] The Center for Snow and Avalanche Studies (CSAS; www.snowstudies.org) provides ground-based observations of temperature, relative humidity, snowpack depth, and longwave downward flux in the San Juan Mountains, at the Senator Beck Study Plot $\left(37.9^{\circ} \mathrm{N}-107.725^{\circ} \mathrm{W}\right.$ at $3719 \mathrm{~m}$, in alpine tundra), and at the Swamp Angel Study Plot $\left(37.9^{\circ} \mathrm{N}-\right.$ $107.711^{\circ} \mathrm{W}$ at $3368 \mathrm{~m}$, in a subalpine meadow). The longwave fluxes are measured with a Kipp and Zonen model CG4 pyrgeometer, which has a $180^{\circ}$ field of view. The CG4 is designed to minimize the effects of window heating in direct sunlight during daylight measurements. The air temperature and relative humidity are measured with a Campbell-Vaisala model CS500-U Humitter ${ }^{\circledR}$. All measurements are obtained every $5 \mathrm{~s}$ and available as hourly averages during the period 2005-2010. Measurements were removed whenever instances of snow accumulation on the radiometer at Swamp Angel were detected based on the correlation between a sudden increase in longwave flux and in snow depth that did not occur simultaneously at Senator Beck.
This left a total of more than $44,000 \mathrm{~h}$ at both sites when all measurements of interest were available at both locations. Because there is no cloud-observing system in place at either site, we rely on the satellite observations for cloud clearing.

[9] The NASA satellites Terra and Aqua were launched in 1999 and 2002, respectively, and both host the Moderate Resolution Imaging Spectroradiometer (MODIS) [Salomonson et al., 1989] and the Cloud and Earth's Radiant Energy System (CERES) [Wielicki et al., 1996]. The MODIS has 36 spectral bands ranging from 0.4 to $14.4 \mu \mathrm{m}$. Two bands are imaged at $250 \mathrm{~m}$ resolution, another five at $500 \mathrm{~m}$, and the remaining bands at $1 \mathrm{~km}$. The swath width is $2330 \mathrm{~km}$, and global coverage is obtained every one to two days. MODIS precipitable water vapor (PWV) retrievals [Seemann et al., 2003] are available in the MOD07/MYD07 files (collection 5) [Seemann et al., 2006] and collected, for both platforms, for 2005-2010 at times when Terra or Aqua overpasses the San Juan region. Precipitable water vapor is the integration of retrieved moisture profiles obtained using a statistical regression method based on seven MODIS infrared channels [Seemann et al., 2006]. Seemann et al. [2006] reported that the MODIS PWV (of collection 5) has a small dry bias $(\sim 0.5 \mathrm{~mm})$ and an uncertainty of $2 \mathrm{~mm}$ when PWV $<15 \mathrm{~mm}$ for a continental location (Southern Great Plains Department of Energy Atmospheric Radiation Measurement site). MODIS PWV is only retrieved when the MODIS cloud mask [Ackerman et al., 1998] indicates with high confidence that at least $20 \%$ of a pixel is clear. However, we only use retrievals when the cloud mask indicates, with $99 \%$ confidence, that the entire $5 \mathrm{~km} \times 5 \mathrm{~km}$ pixel is clear.

[10] The CERES scanning radiometer measures top-ofthe-atmosphere (TOA) radiances in three broadband channels $(0.2-100,0.2-5$, and $8-12 \mu \mathrm{m})$ at $20 \mathrm{~km}$ resolution. Fluxes are obtained using an angular distribution model. Then vertical profiles of longwave and shortwave fluxes are calculated using a radiative transfer model [Fu and Liou, 1993] that incorporates MODIS cloud retrievals and the GEOS-4 (more recently GEOS-5) Data Assimilation System [Bloom et al., 2005] reanalysis meteorological profiles. The calculated TOA flux is then compared with the measured TOA flux, and the cloud properties and/or meteorological profiles are adjusted before a new radiative transfer calculation is performed and a TOA flux closer to the observation is obtained [Charlock et al., 1997; Charlock et al., 2006]. The fluxes are calculated at five tropospheric levels, and since they are constrained by the TOA fluxes, we refer to these surface-level fluxes as "constrained" fluxes. CERES cloud and radiative swath files provide computed constrained fluxes up to February 2010, as well as surface-only fluxes calculated with two different models (models A and B) [Gupta et al., 2010]. In section 4 we show how the different models compare with the ground-based observations and explain why the surface-only fluxes from models A and $\mathrm{B}$ were not chosen. These files are collected for the same times as MODIS, and clear-sky surface longwave fluxes are extracted. We collect the clear-sky downward longwave surface fluxes (hereafter referred to as the longwave downward radiation, LDR).

[11] Terra and Aqua overpass the Senator Beck Basin twice a day, and we extract PWV in the $5 \mathrm{~km}$ pixel closest to the site (i.e., the distance between the pixel center and one of the sites is less than $0.05^{\circ}$ ). We perform the same operation 
for CERES-computed fluxes. Because CERES has a larger field of view than MODIS, this may cause some errors when scattered clouds are present, i.e., the fluxes may be overestimated when clouds present in the $20 \mathrm{~km}$ region are not in the $5 \mathrm{~km}$ pixel observed by MODIS. We next investigated the potential errors that would be introduced by averaging the MODIS PWV over a $20 \mathrm{~km} \times 20 \mathrm{~km}$ region centered on the site as compared with the $5 \mathrm{~km} \times 5 \mathrm{~km}$ retrievals. We found an average difference between the 20 and $5 \mathrm{~km}$ PWV estimates of $0.3 \pm 0.7 \mathrm{~mm}$, with a scatter confined within $2 \mathrm{~mm}$, which is within the retrieval uncertainty reported by Seemann et al. [2006]. Consequently, we decided to retain only the $5 \mathrm{~km}$ pixel closest to the sites for MODIS PWV to ensure a better match with the ground-based sites.

[12] There were a total of 8147 MODIS measurements performed in close proximity to the sites for the 2005-2010 period, of which 4012 were available in clear-sky situations. These coincided with a ground-based measurement in 2318 cases. There are no archived CERES observations available after March 2010, and some of the files are missing during the other months, removing 1184 points from our data pool. Sometimes the LDR flux estimates are erroneous (values greater than $10,000 \mathrm{~W} \mathrm{~m}^{-2}$ ), and this removes another 83 points. In total, there were 1047 hourly coincident instances when ground-based, MODIS, and CERES measurements were available in clear-sky conditions. This yields an average of 15 hourly clear-sky measurements per month, but we require that there be at least 10 hourly coincident measurements per month to calculate the monthly means of humidity and longwave flux. This provides 62 months for comparison.

\section{Comparison Between Satellite-Retrieved PWV and Ground-Based Specific Humidity}

[13] To our knowledge, MODIS PWV retrievals have not been evaluated over high-elevation regions. Because of the large variations in altitude to be expected in the $5 \mathrm{~km} \times 5 \mathrm{~km}$ MODIS pixels and the extreme dryness these locations may experience, errors may occur and need to be evaluated. One major obstacle is that PWV is rarely measured from the ground, and radiosoundings are not available in these remote locations. Therefore, we compare ground-based specific humidity $q$ with satellite retrievals of PWV and refer to previous similar comparisons, such as those of Smith [1966], Liu [1986], Adedokun [1986], or Ruckstuhl et al. [2007] (hereafter referred as R07), who used GPS-derived PWV in the Alps.

[14] First, we perform this comparison for the CSAS sites. Figure 1a and Figure 2 show that the relationship between $q$ and PWV is nonlinear for both the monthly and hourly coincident cases, with the slope for low values of $q$ being about half that for high values of $q$. If we examine specific humidities above and below $2.5 \mathrm{gkg}^{-1}$ separately, we find that the relationships are nearly linear in both ranges with a slope of about $2.5 \mathrm{~mm}\left(\mathrm{gkg}^{-1}\right)^{-1}$ for values above $2.5 \mathrm{gkg}^{-1}$ and about $1 \mathrm{~mm}\left(\mathrm{gkg}^{-1}\right)^{-1}$ for values below $2.5 \mathrm{gkg}^{-1}$. The slope at Senator Beck for winter is about the same as R07 found for their highest site (Jungfraujoch, $3580 \mathrm{~m}$ ), while the slope for summer is closer to the estimate they found for their lower-altitude sites (e.g., Payerne, $498 \mathrm{~m}$ ). This is consistent whether using hourly coincident or monthly observations (Figures 1a and 2), although hourly coincident observations display a larger scatter, particularly in summer. We find that a polynomial fit encompasses both regimes with a higher correlation coefficient than the two linear fits and is consistent with earlier studies such as those of Liu [1986] for global oceans and Adedokun [1986] for West Africa. However, as shown by Adedokun [1986] and later by Gautam et al. [1992], this polynomial relationship is not universal and changes with location. Adedokun [1989] finds that a simple polynomial relationship of the type $\mathrm{PWV}=a q^{b}$ fits their observations over West Africa during the rain season but the coefficients change during the dry season.

[15] To explore further the possibility of a more universal PWV- $q$ relationship, we used ground-based observations collected between 2001 and 2010 at 12 weather stations across the United States, provided by the National Climatic Data Center through their Climate Data Online service. These stations were arbitrarily chosen so their locations cover most climatic regimes available in North America (see Table 1) and their altitude varies from $3 \mathrm{~m}$ (Fort Lauderdale, Florida) to $2388 \mathrm{~m}$ (Yellowstone Lake, Wyoming). Hourly measurements of relative humidity, temperature, and pressure were combined and averaged to obtain monthly means of ground-based specific humidities. Clear-sky conditions were ensured by using ceiling measurements that were also provided in the files. The specific humidities were then compared with colocated MODIS level-3 monthly PWV retrievals.

[16] Combining these different locations, we find that for $q>4 \mathrm{gkg}^{-1}$, the relationship is similar for all locations (Figure $3 \mathrm{a}$ and Table 1) with a linear fit and an average slope of $2.5 \pm 0.3 \mathrm{~mm}\left(\mathrm{gkg}^{-1}\right)^{-1}$. This is consistent with the result found by R07 for their lowest locations and with Figure 1a. However, for those sites that are dry enough for $q$ to become less than $3 \mathrm{gkg}^{-1}$ (Figure $3 \mathrm{~b}$ and Table 1), the slope of the linear fit obtained for all $q$ measurements less than this threshold decreases with altitude from $3.1 \mathrm{~mm}\left(\mathrm{gkg}^{-1}\right)^{-1}$ at Augusta (Maine, $109 \mathrm{~m})$ to $0.6 \mathrm{~mm}\left(\mathrm{gkg}^{-1}\right)^{-1}$ at Yellowstone Lake (Wyoming, $2388 \mathrm{~m}$ ). These slopes are only given in Table 1 for the sites that had enough points to perform the regression (at least 25) and for which the correlation coefficient was greater than 0.6. A nonlinear fit of the type suggested by Adedokun [1986] was also tested, but the coefficients also changed among the different locations (not shown). Figure $3 \mathrm{~b}$ suggests that the range of MODIS PWV values diminishes with altitude at a faster rate than does $q$. This is consistent with the work by R07, who found that GPS-derived PWV decreased faster with elevation than $q$ in the Alps. However, here we find that this is only true for low values of $q$ and does not apply at Senator Beck during summer months. For these months, we suspect that largescale conditions affect the entire atmospheric column humidity content more than they do the surface. However, it is difficult to establish why this was not observed by R07 in their study in the Alps. It is unclear whether the enhanced PWV decrease with increasing altitude is caused by a more rapid depletion of humidity in the entire atmospheric column (as observed by MODIS) than close to the surface where land-air interactions may provide a steady source of moisture even at high elevations. We speculate that the altitude dependency of PWV for low-humidity regimes is real. 
(a) MODIS PWV vs. GB q

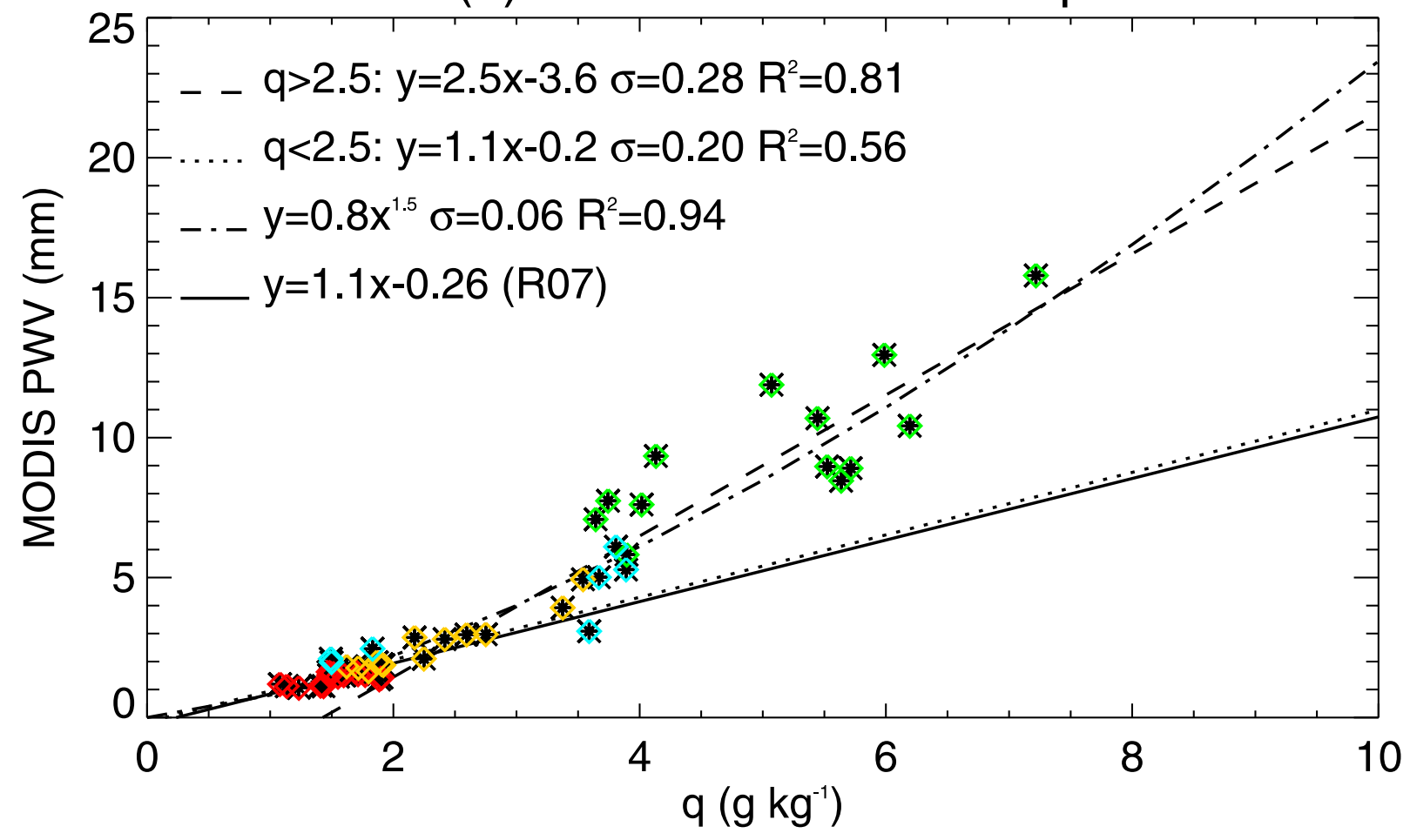

(b) CERES vs. GB LDR

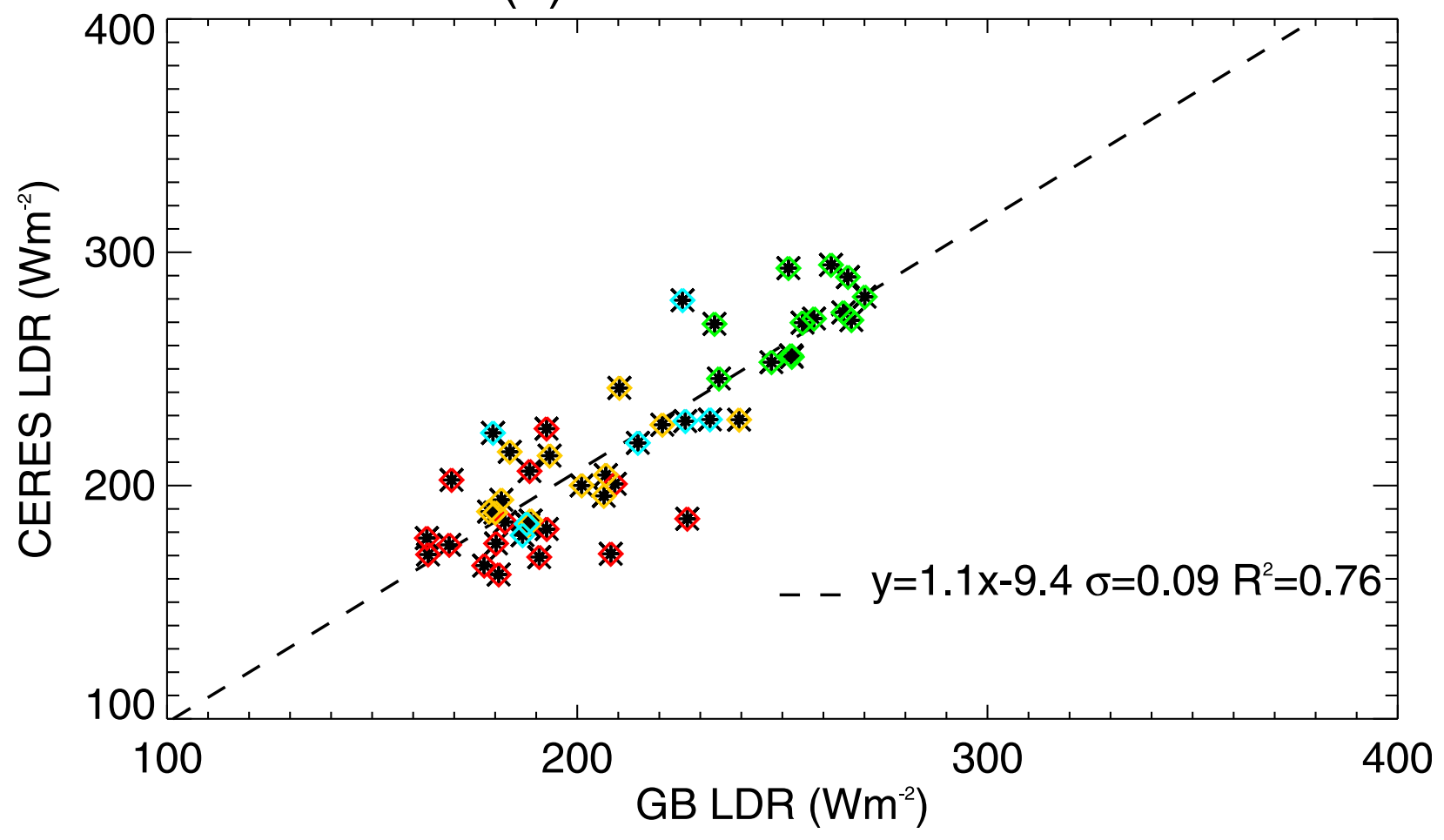

Figure 1. At the CSAS sites, for 2005-2010. (a) Comparison of monthly mean of MODIS PWV and ground-based $q$. Each line represents a fit: The dashed and dotted lines give a linear fit for $q>2.5 \mathrm{gkg}^{-1}$ and $q<2.5 \mathrm{gkg}^{-1}$, respectively, the dot-dash line is a polynomial fit, and the solid line is the linear fit that R07 found for clear-sky observations at Jungfraujoch in the Alps. The first three fits are given with the standard deviation of the slope $(\sigma)$ and the squared correlation coefficient. (b) Relationship between monthly CERES and ground-based LDR. The dashed line shows the linear fit. For Figures 1a and 1b, the colors represent each season: red, winter; yellow, spring; blue, fall; and green, summer. 

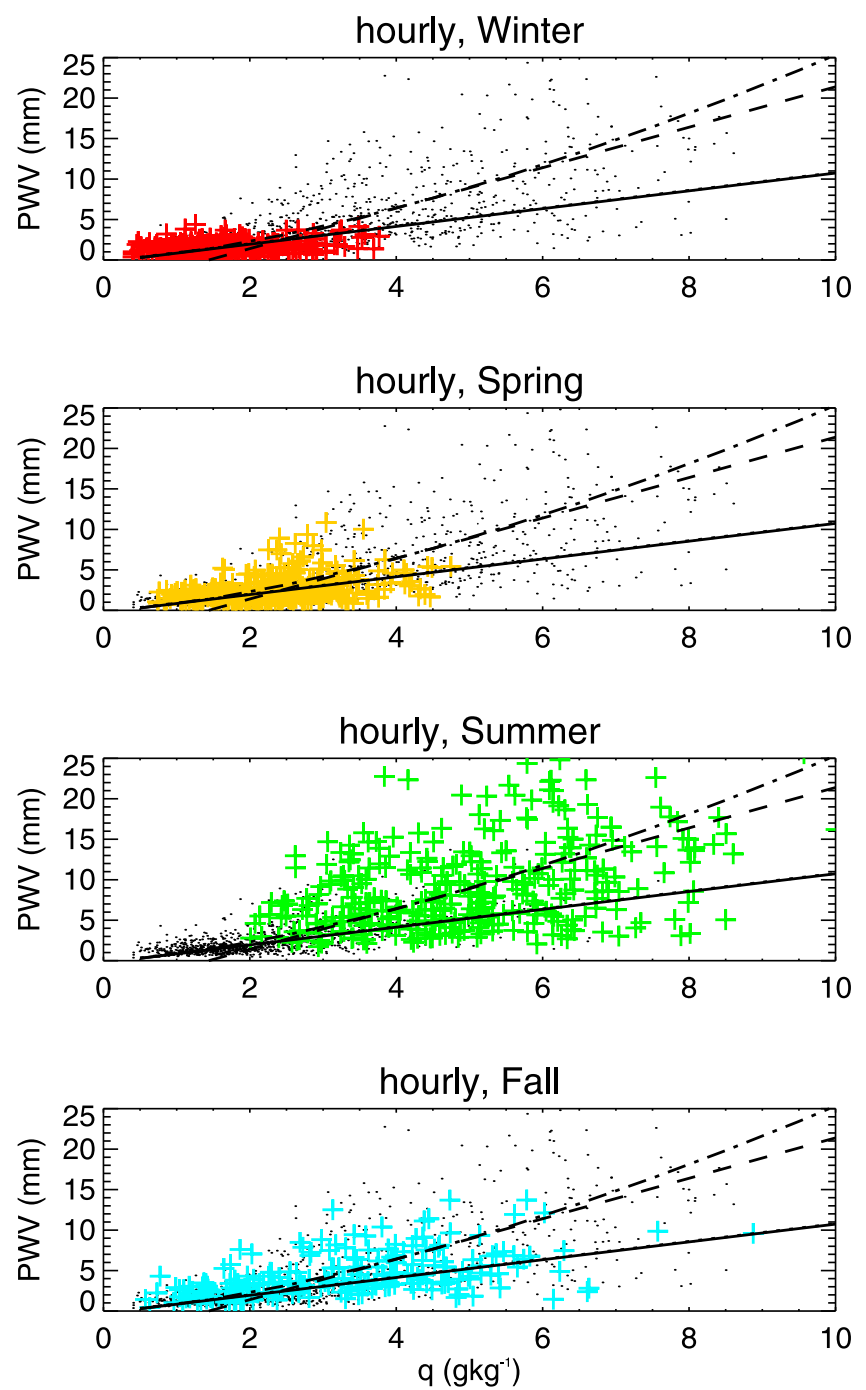

Figure 2. MODIS PWV versus ground-based specific humidity $q$ at the CSAS sites for hourly coincident observations in winter, spring, summer, and fall. The black dots are the same in all panels and show all seasons. The lines are identical to those of Figure 1, with the dashed line showing the linear fit for $q>2.5 \mathrm{gkg}^{-1}$ and the dotted line for $q<2.5 \mathrm{gkg}^{-1}$ (note that the dotted line is almost superimposed on the solid line). The dot-dash line is a polynomial fit, and the solid line is the linear fit that R07 found for clear-sky observations at Jungfraujoch in the Alps.

[17] We also explored an empirical relationship proposed by Smith [1966] that relates PWV and $q$ through a parameter $\lambda$ :

$$
\mathrm{PWV} \approx \frac{q P_{0}}{g(\lambda+1)},
$$

where $P_{0}$ is the surface pressure and $g$ is the gravitational acceleration. Smith [1966; equation (7)] uses the mixing ratio, while here we use $q$ instead. Using monthly observations of the 12 weather stations, we calculated $\lambda$ and checked its dependency on altitude and $q$ (see Table 2 and Figure 4). For all sites that were at an altitude below $1000 \mathrm{~m}, \lambda$ is fairly stable for all values of $q$ (small standard deviation and small difference between all $q$ values and high $q$ values) and consistent with the values calculated by Smith [1966, Table 1] for similar latitudes. Figure 4 shows a slight change in values of $\lambda$ for $q$ less than $5 \mathrm{gkg}^{-1}$ for all sites below $1000 \mathrm{~m}$, but for sites above $1000 \mathrm{~m}$, there is a large scatter in $\lambda$ (large standard deviation and large difference between all $q$ values and high $q$ values), suggesting that the relationship proposed by Smith [1966] may not describe high elevations as well as low elevations. This additional result confirms the dependency of PWV on elevation in dry conditions.

[18] These different comparisons suggest that MODIS PWV retrievals are accurate at high elevations and relate to surface $q$ in a manner found in previous studies. We found no reason to believe that the accuracy of the retrievals is degraded with altitude. For the driest conditions, the dependency of PWV on elevation is consistent with the earlier results of R07 that were obtained in a different location and with a different type of instrumentation.

\section{Comparison of Ground-Based and Satellite- Derived Longwave Radiation}

[19] A major issue with satellite-derived surface fluxes is that they are not measured directly, but they are calculated with a radiative transfer model based on ancillary cloud and meteorological information. In particular, longwave fluxes are strongly dependent on the surface and near-surface properties [Schmetz, 1989; Zhang et al., 2006, 2007] and are thus decorrelated from TOA measurements. Zhang et al. [2006] report that surface air temperature errors of $2-4 \mathrm{~K}$ can cause errors in surface downward longwave fluxes of up to $15 \mathrm{~W} \mathrm{~m}^{-2}$. The second largest source of error is the column PWV, in which an uncertainty of $20 \%-25 \%$ can cause errors up to $10 \mathrm{~W} \mathrm{~m}^{-2}$ [Zhang et al., 2006].

[20] CERES constrained fluxes have been evaluated against ground sites of the CERES/ARM Validation Experiment network, and a low bias of $-10 \mathrm{~W} \mathrm{~m}^{-2}$ and a standard deviation of $9 \mathrm{~W} \mathrm{~m}^{-2}$ were found (see www-cave. larc.nasa.gov/cave for access to online interactive assessment). Only 7 out of 64 sites are above $1000 \mathrm{~m}$, and the online interactive validation tool indicates a larger bias of about $-20 \mathrm{~W} \mathrm{~m}^{-2}$ with a standard deviation of about $11 \mathrm{~W} \mathrm{~m}^{-2}$ for 2000-2006 at the Table Mountain site in Colorado $(1689 \mathrm{~m})$. Here we assess the performance of the CERES surface flux calculations at higher elevations using the CSAS measurements. We directly compare the CEREScomputed constrained LDR with surface-based observations at the hourly coincident and monthly time scales.

[21] In section 2, we explained that the CERES files contain three different downward longwave surface fluxes: surface-only model A [Inamdar and Ramanathan, 1997], surface-only model B [Gupta et al., 1992], and the "constrained" surface flux. Using the ground-based hourly coincident fluxes, we evaluate the accuracy of the three CERES fluxes. Figure 5 shows scatterplots of the three comparisons when CERES observed the CSAS sites during the 5 year period. Model A (Figure 5b) gives overestimated fluxes for the Senator Beck Basin, and only a limited number of points are computed (only computed when absolutely clear). Model B fluxes (Figure 5c) are also overestimated, and the difference increases with LDR. There is more scatter in the 
Table 1. Comparison of Monthly Mean Specific Humidity $q$ From Weather Stations Versus MODIS PWV for 2001-2010: Locations, Elevations, and Slopes of Linear Fit for $q>4 \mathrm{~g} \mathrm{~kg}^{-1}$ and $q<3 \mathrm{~g} \mathrm{~kg}^{-1}$

\begin{tabular}{lccc}
\hline \multicolumn{1}{c}{ Location } & Elevation $(\mathrm{m})$ & $\begin{array}{c}\text { Slope }\left(\mathrm{mm}\left(\mathrm{gkg}^{-1}\right)^{-1}\right) \text { for } \\
q>4 \mathrm{~g} \mathrm{~kg}^{-1}\left(R^{2}\right)\end{array}$ & $\begin{array}{c}\left.\text { Slope }\left(\mathrm{mm}(\mathrm{gkg})^{-1}\right)^{-1}\right) \text { for } \\
q<3 \mathrm{gg}^{-1}\left(R^{2}\right)\end{array}$ \\
\hline Fort Lauderdale, Florida & 3 & $2.8(0.88)$ & - \\
San Diego, California & 8 & $2.6(0.77)$ & - \\
New York City, New York & 9 & $2.4(0.94)$ & $2.8(0.66)$ \\
Augusta, Maine & 109 & $2.5(0.94)$ & $3.1(0.86)$ \\
Raleigh, North Carolina & 133 & $2.5(0.95)$ & - \\
La Crosse, Wisconsin & 199 & $2.2(0.96)$ & $2.3(0.82)$ \\
Austin, Texas & 200 & $2.4(0.95)$ & - \\
Columbia, Missouri & 273 & $2.3(0.94)$ & - \\
Helena, Montana & 1179 & $2.8(0.81)$ & $1.7(0.65)$ \\
Stampede Pass, Washington & 1209 & $2.8(0.84)$ & - \\
Bryce Canyon, Utah & 2313 & $2.1(0.18)$ & - \\
Yellowstone Lake, Wyoming & 2388 & $2.9(0.81)$ & $0.6(0.43)$ \\
\hline
\end{tabular}

"constrained" surface flux product (Figures 5a, 5d, 5e, and $5 \mathrm{f}$ ), but overall the agreement with ground observations is better than with the surface-only computed fluxes, as the average biases for all seasons are $6.5,26.1$, and $53.0 \mathrm{~W} \mathrm{~m}^{-2}$ for the constrained model, model $\mathrm{A}$, and model B, respectively. Therefore, we decided to use the constrained CERES product for the rest of this study.

[22] The constrained fluxes show several clusters of outliers, depending on the season. Spring and fall have the least scatter for the hourly coincident observations (Figure 5e). In summer there is a cluster of outliers where CERES LDR is larger than ground-based values (Figure 5f). This may occur when clouds are present in the CERES field of view but not visible to the ground-based radiometer or in the $5 \mathrm{~km}$ MODIS pixel (i.e., in cases of scattered clouds). The opposite occurs in winter, when there is a significant cluster of ground-based fluxes with LDR larger than CERES values (Figure 5d). This may be caused by clouds present over the site but not detected by MODIS; passive radiometers have difficulties in detecting clouds over bright surfaces such as snow and ice, as it becomes difficult to delineate a bright object over a bright background [Ackerman et al., 2008]. These outliers cannot be easily eliminated from our study because of the lack of an efficient cloud-clearing procedure, but monthly averaging reduces these effects. A thorough examination of these outliers is not possible at present with the observations at our disposal but will be the object of further investigation.

[23] Figure $1 \mathrm{~b}$ shows the comparison between monthly means of CERES-computed and ground-based observed LDR. The fit to the linear regression line has a squared correlation coefficient of 0.76 and a slope of $1.1 \pm 0.1$ (unitless). On average, for all seasons, CERES fluxes are overestimated by $7 \mathrm{~W} \mathrm{~m}^{-2}$ with a standard deviation of $19 \mathrm{~W} \mathrm{~m}^{-2}$ (a bias similar to the one obtained with hourly coincident observations). Surprisingly, we find a positive bias instead of the negative bias found by the CERES/ARM Validation Experiment cited above. This may be due to a dependency of the bias on elevation. The red points are for winter when LDR is lowest, with more scatter than in other seasons, as discussed above. We also note that the range of fluxes for the groundbased observations is slightly wider in winter than in other seasons, i.e., there is more variability in winter in this mountain basin, classified as a "continental" snow climate [Mock and Birkeland, 2000]. The green points are for summer, when LDR is largest, and the CERES values are biased somewhat high compared with those of observations, consistent with the cluster of overestimated CERES LDR in Figure 5f.

\section{Relationship Between Surface Downward Longwave Flux and Water Vapor}

[24] If satellite retrievals are to be used to investigate the water vapor feedback loop at high elevations, they must be

(a)

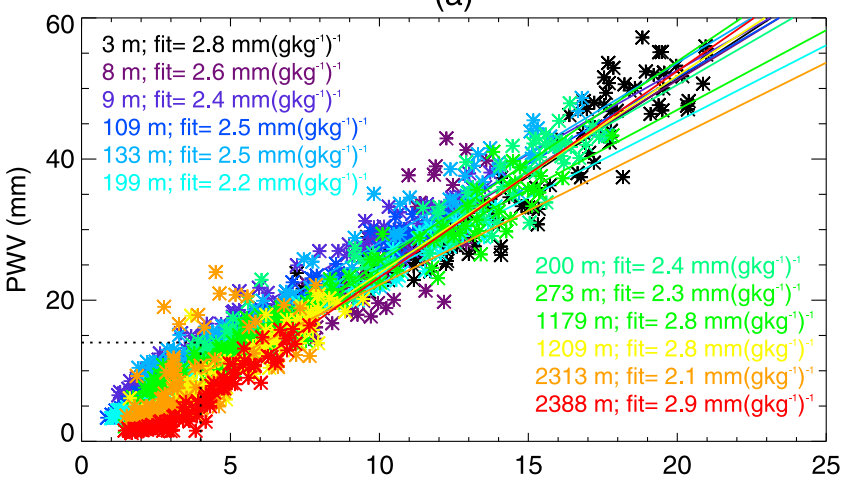

(b)

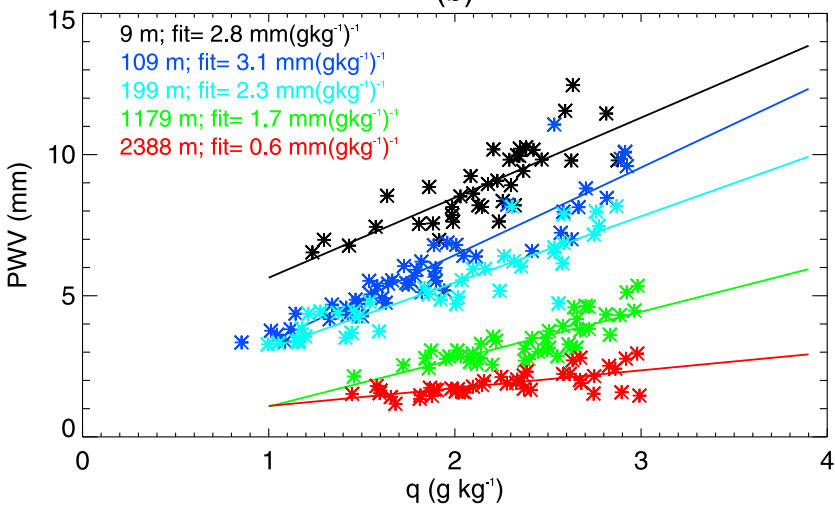

Figure 3. (a) Comparison between monthly MODIS PWV retrieval and ground-based measurements of $q$ for 12 weather stations across the United States for 2001-2010. The elevation and slope of a linear fit obtained for $q>4 \mathrm{~g} \mathrm{~kg}^{-1}$ are given. (b) Same as Figure 3a but only for $q<3 \mathrm{~g} \mathrm{~kg}^{-1}$ for those stations that were dry enough. 
Table 2. Monthly Mean and Standard Deviation of Smith's [1966] $\lambda$ Parameter that Relates PWV and $q$ for All $q$ Values and $q>5 \mathrm{gkg}^{-1}$, at 12 Weather Stations in the Contiguous United States, for 2001-2010

\begin{tabular}{|c|c|c|c|}
\hline Location & Elevation (m) & $\lambda$ for All $q($ mean $\pm \sigma)$ & $\lambda$ for $q>5 \mathrm{gkg}^{-1}($ Mean $\pm \sigma)$ \\
\hline Fort Lauderdale, Florida & 3 & $3.22 \pm 0.46$ & $3.22 \pm 0.46$ \\
\hline San Diego, California & 8 & $3.16 \pm 0.63$ & $3.19 \pm 0.61$ \\
\hline New York City, New York & 9 & $2.08 \pm 0.56$ & $2.51 \pm 0.35$ \\
\hline Augusta, Maine & 109 & $2.42 \pm 0.39$ & $2.70 \pm 0.30$ \\
\hline Raleigh, North Carolina & 133 & $2.33 \pm 0.57$ & $2.69 \pm 0.36$ \\
\hline La Crosse, Wisconsin & 199 & $2.97 \pm 0.47$ & $3.23 \pm 0.033$ \\
\hline Austin, Texas & 200 & $2.83 \pm 0.44$ & $2.93 \pm 0.41$ \\
\hline Columbia, Missouri & 273 & $2.83 \pm 0.53$ & $3.11+0.40$ \\
\hline Helena, Montana & 1179 & $4.19 \pm 1.32$ & $2.82 \pm 0.44$ \\
\hline Stampede Pass, Washington & 1209 & $3.91 \pm 1.22$ & $3.16 \pm 0.50$ \\
\hline Bryce Canyon, Utah & 2313 & $2.07 \pm 2.19$ & $2.55 \pm 1.08$ \\
\hline Yellowstone Lake, Wyoming & 2388 & $5.68 \pm 3.42$ & $3.10 \pm 0.55$ \\
\hline
\end{tabular}

able to capture the sensitivity of LDR to changes in water vapor, and in particular be able to capture the high sensitivities when the atmosphere is dry. In this section, we compare satellite-derived sensitivities with those obtained from in situ observations, as well as with results of R07. Figure 6 shows the relationship obtained when using ground-based LDR and $q$ and the relationship obtained with CERES LDR and MODIS PWV. In each plot we give the fit obtained with the observations used here as well as the fits that R07 found for sites in the Alps. In the Alps, using ground-based measurements, R07 reported a fit of LDR $=150.2 q^{0.35}$ for clear sky and $181.4 q^{0.29}$ for all-sky conditions. We find here, for clearsky conditions, LDR $=163.6 q^{0.27}$. Figure 6 a reveals that the Senator Beck observations agree best with R07's clear-sky fit, but some of the summer measurements depart from the clear-sky fit, which causes a discrepancy in the exponent. The relationship found here using CERES and MODIS is also consistent with that found in the Alps using GPS for PWV measurements (R07), albeit for all-sky measurements (Figure 6b). The fact that both satellite-based and surface measurements are affected by the same problem in summer (the fit deviates from the R07 clear-sky fit) could be related to how the cloud masking is done at Senator Beck, i.e., as also suggested by Figure $5 \mathrm{f}$.

[25] To verify that the relationship we find using the satellite observations is robust, we extend the number of locations to include Davos $\left(46.8^{\circ} \mathrm{N}-9.81^{\circ} \mathrm{E}, 1801 \mathrm{~m}\right)$ and Jungfraujoch $\left(46.55^{\circ} \mathrm{N}-7.98^{\circ} \mathrm{E}, 1833 \mathrm{~m}\right)$ in the Alps, Storm Peak in the northwestern Colorado Rockies $\left(40.455^{\circ} \mathrm{N}-\right.$ $\left.106.744^{\circ} \mathrm{W}, 2665 \mathrm{~m}\right)$, and Ge'er $\left(32.30^{\circ} \mathrm{N}-80.05^{\circ} \mathrm{E}\right.$, $4952 \mathrm{~m})$, Naqu $\left(31.29^{\circ} \mathrm{N}-92.04^{\circ} \mathrm{E}, 4795 \mathrm{~m}\right)$, and Lhasa $\left(29.40^{\circ} \mathrm{N}-91.08^{\circ} \mathrm{E}, 4476 \mathrm{~m}\right)$ over the Tibetan Plateau. For each of these sites, we extract the CERES LDR and MODIS PWV monthly means (from level 3 files, using CERES AVG for monthly constrained fluxes) and plot the relation between the two observations for all sites and all seasons in Figure 7. Note that the altitudes given here correspond to the average altitude of the $1^{\circ}$ grid cell that encompasses the site, as provided in the MODIS files. Thus they do not necessarily match the actual altitude at the latitude-longitude point indicated above, i.e., the Senator Beck Basin is at $2792 \mathrm{~m}$ rather than above $3500 \mathrm{~m}$.

[26] The overall relation between LDR and PWV is $\mathrm{LDR}=156.6 \mathrm{PWV}^{0.22}$, with $95 \%$ of the variance explained. The scatter around the fit increases with PWV, but there is no obvious dependency on altitude. Because the satellite observations are tested here for their ability to provide reliable fluxes and water vapor measurements in dry conditions, Figure $7 \mathrm{~b}$ expands the scale of Figure $7 \mathrm{a}$ to show the relationship for low values of PWV (PWV $<5 \mathrm{~mm}$ ) more clearly. A regression is performed for this subset: $\mathrm{LDR}=154.1$ $\mathrm{PWV}^{0.25}$ with $91 \%$ of the variance explained. Since this fit is very close to the clear-sky fit shown by R07, it provides evidence that MODIS and CERES obtain the high sensitivities under dry conditions that are found at high elevations, and they can be reliably used to examine the water vapor feedback loop. We found that the relationship is very similar when using the hourly coincident data (not shown), even though the variability is then greater. With this latter fit, we find that a decrease in PWV of $1 \mathrm{~mm}$ from $P W V=2 \mathrm{~mm}$ causes a decrease in longwave flux of $29 \mathrm{~W} \mathrm{~m}^{-2}$ while a decrease in $q$ of $1 \mathrm{gkg}^{-1}$ at Senator Beck from $2 \mathrm{gkg}^{-1}$ causes a decrease in longwave flux of $34 \mathrm{~W} \mathrm{~m}^{-2}$, with both data sets giving very similar sensitivities.

\section{Conclusions}

[27] Although there has been progress in identifying climate change in mountain regions, there is still considerable

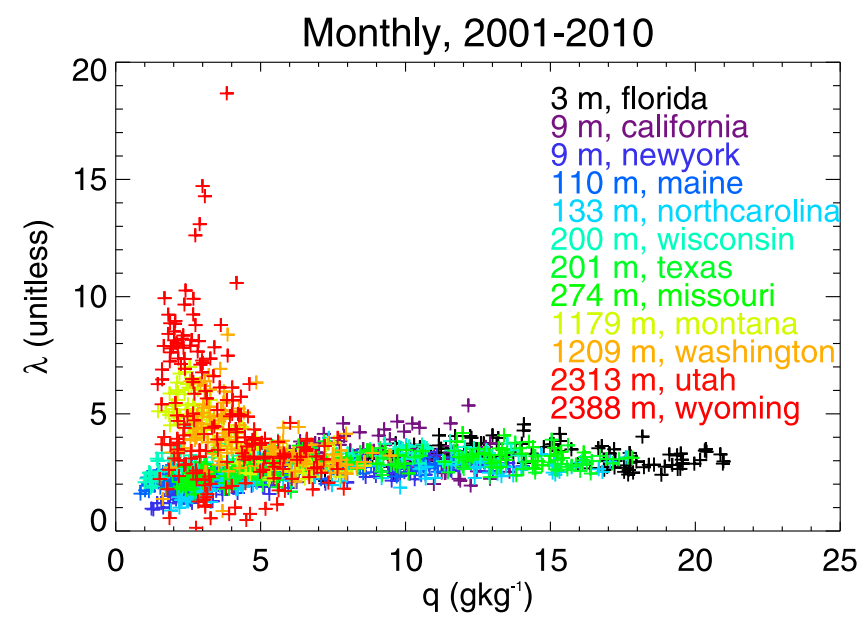

Figure 4. Smith's [1966] parameter $\lambda$ as a function of $q$ for 12 weather stations across the contiguous United States, using monthly means of MODIS PWV, ground-based $q$, and surface pressure, for 2001-2010. 
(a) Constrained

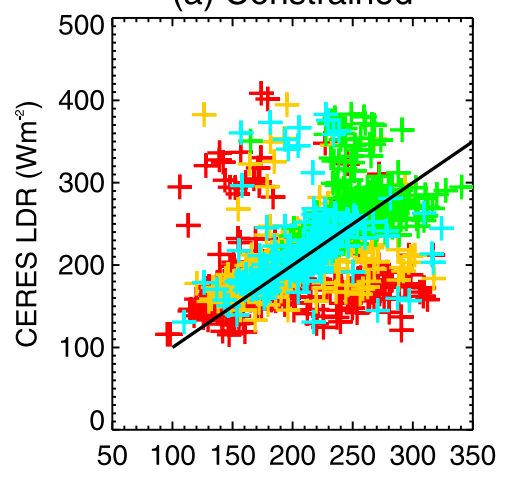

(d) Winter

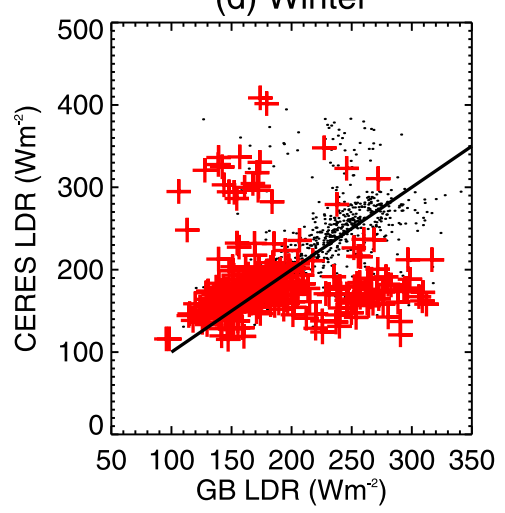

(b) Model A

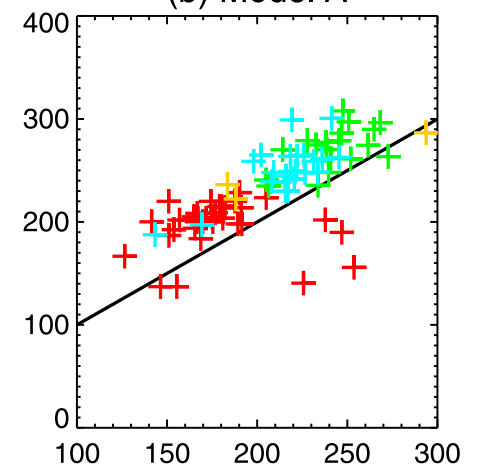

(e) Spring+Fall

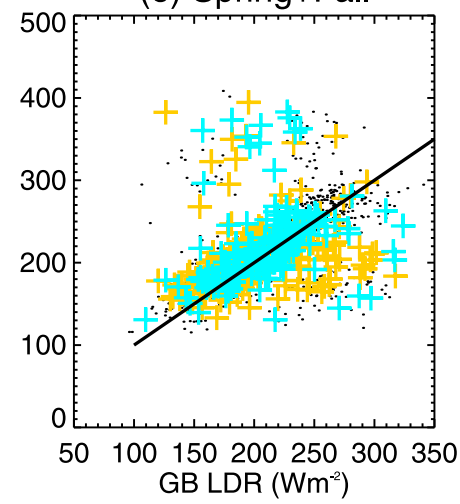

(c) Model B

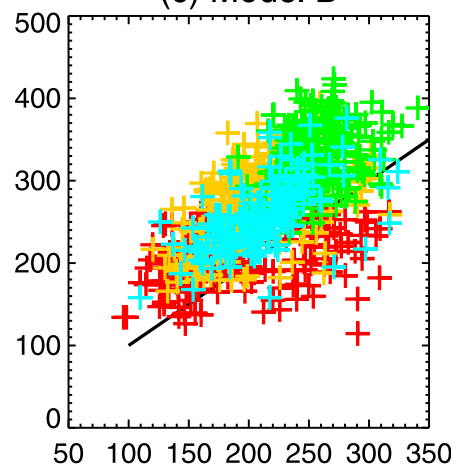

(f) Summer

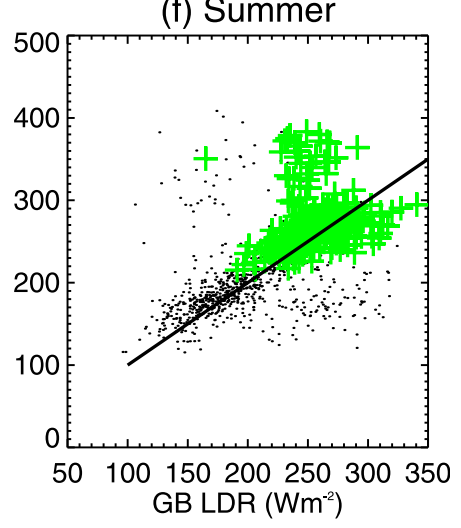

Figure 5. CERES instantaneous surface longwave flux compared with hourly coincident CSAS groundbased fluxes for three CERES products: (a) constrained, (b) model A, and (c) model B. The color coding is similar to that of Figure 1. The relations between CERES constrained and ground-based fluxes are shown separately for (d) winter, (e) spring and fall, and (f) summer.

uncertainty in understanding the feedbacks that contribute to these changes, often different from the global mean or their regional environment. We provide evidence that satellite retrievals can be used to expand on ground-based measurements for both the spatial and temporal scales of important climate variables to investigate potential feedback mechanisms in high-elevation regions, with a focus on the water vapor-LDR feedback loop.

[28] The relationship between MODIS PWV and surface measurements of specific humidity $q$ were consistent with previous studies. We find that PWV and $q$ are linearly correlated for specific humidities greater than $4 \mathrm{gkg}^{-1}$ and the ratio is mostly independent of location and elevation. However, at low values of $q$, the relationship between the two is no longer independent of elevation as PWV begins to decrease more rapidly with increasing elevation than $q$. This is also observed when using the empirical relationship between PWV and $q$ proposed by Smith [1966]; however, our results indicate that the relationship becomes less accurate for low values of $q$ and elevations above $1000 \mathrm{~m}$. MODIS PWV retrievals in low-humidity conditions behave similarly to the GPS estimate tested by Ruckstuhl et al. [2007] in the Alps. Note that GPSderived PWV values are more accurate than those of satellite retrievals [e.g., $\mathrm{Li}$ et al., 2003]. Overall, we do not find that MODIS PWV retrievals degrade with elevation.

[29] We have demonstrated that the CERES monthly averaged LDR (not measured directly but computed), as well as the sensitivities of LDR to changes in water vapor, is consistent with surface measurements at a well-instrumented high-elevation site $(\sim 3500 \mathrm{~m})$ in southwestern Colorado. Because surface longwave fluxes are decoupled from the top-of-the-atmosphere-measured outgoing fluxes outside of the window region and in cloudy conditions [Schmetz, 1989], CERES LDR is computed based on surface and atmospheric profiles of temperature and moisture. As such, its accuracy at high elevation is highly dependent on the accuracy of temperature and moisture information.

[30] The sensitivity of LDR to changes in PWV is also consistent across different mountain ranges (Alps, Rockies, Himalayas). The results are consistent with a similar study performed in the Alps [Ruckstuhl et al., 2007]. Owing to the nonlinear relationship between LDR and water vapor, the sensitivity of LDR to changes in water vapor is much greater when the atmosphere is dry. Since higher elevations are generally drier than lower elevations, we expect a greater sensitivity of longwave fluxes to changes in water vapor at higher elevations. Although hourly coincident comparisons of LDR indicate that there can be significant 
(a) Ground-based

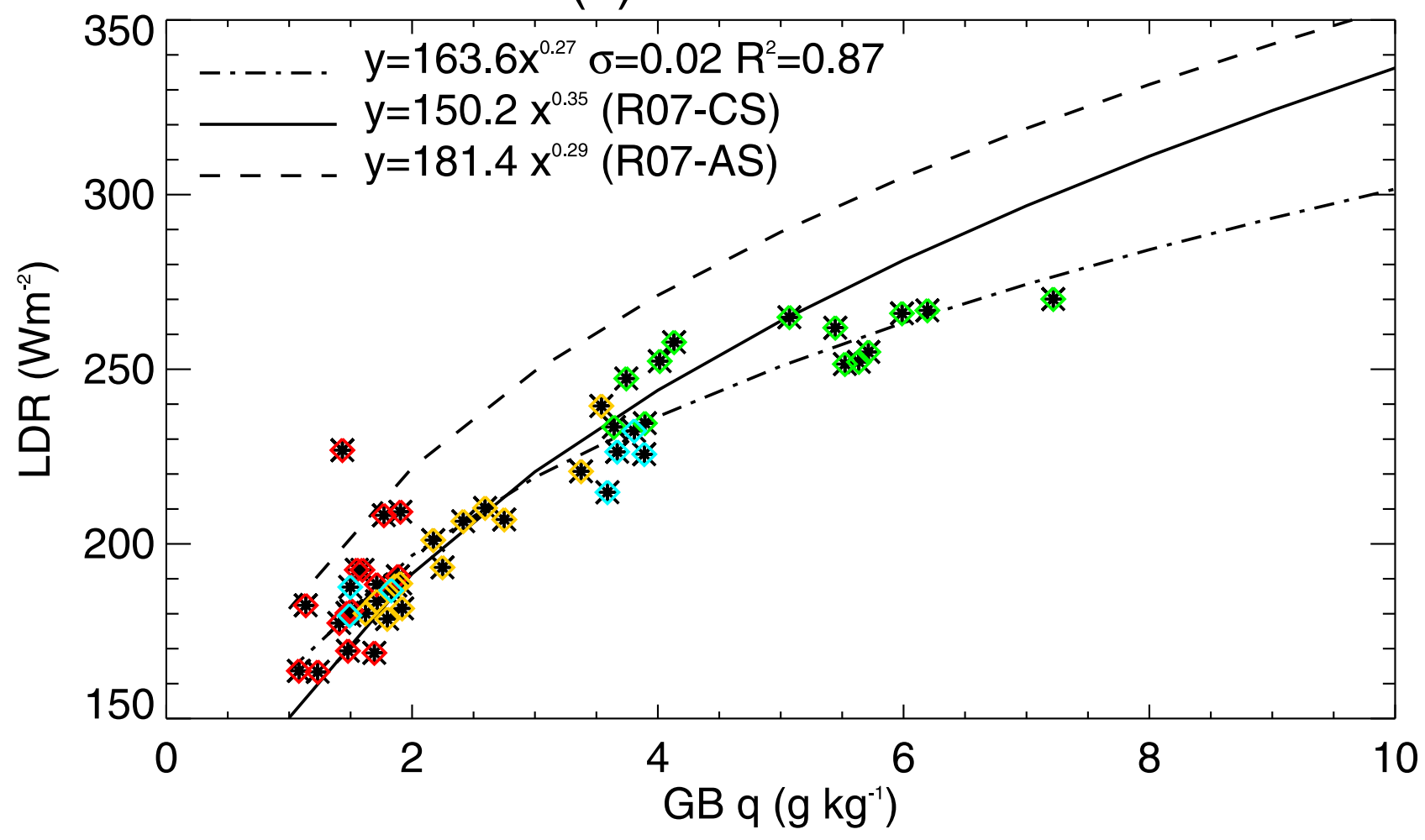

(b) Satellite

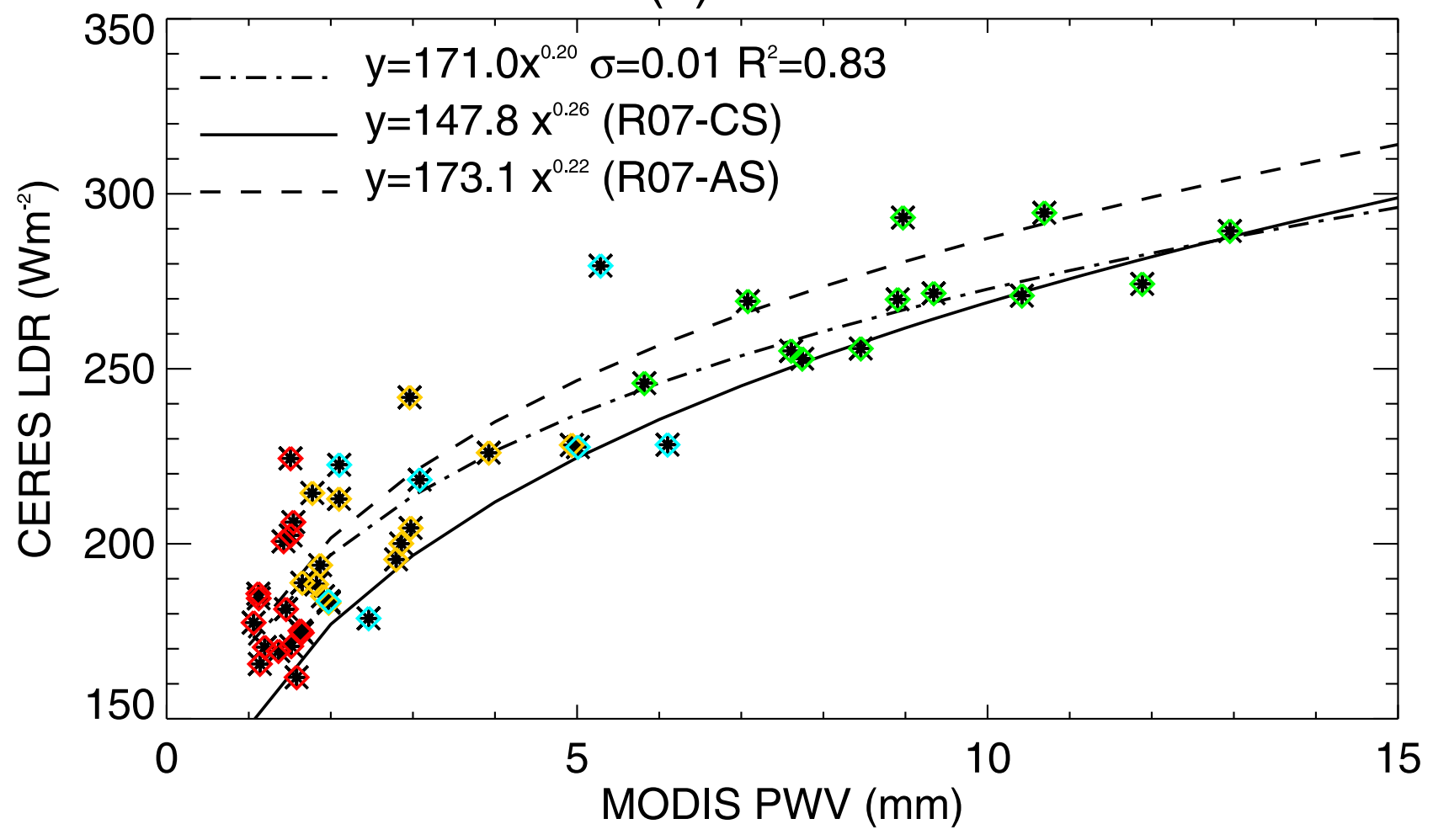

Figure 6. Monthly mean LDR (a) ground-based measurement versus specific humidity and (b) CERES versus MODIS PWV. The color coding is the same as that for Figure 1. Each line represents a polynomial fit: The dotted-dash line is the fit found with the data, the solid line is the fit found by R07 for clear-sky observations, and the dashed line is the fit found by R07 for their all-sky observations. 
(a)

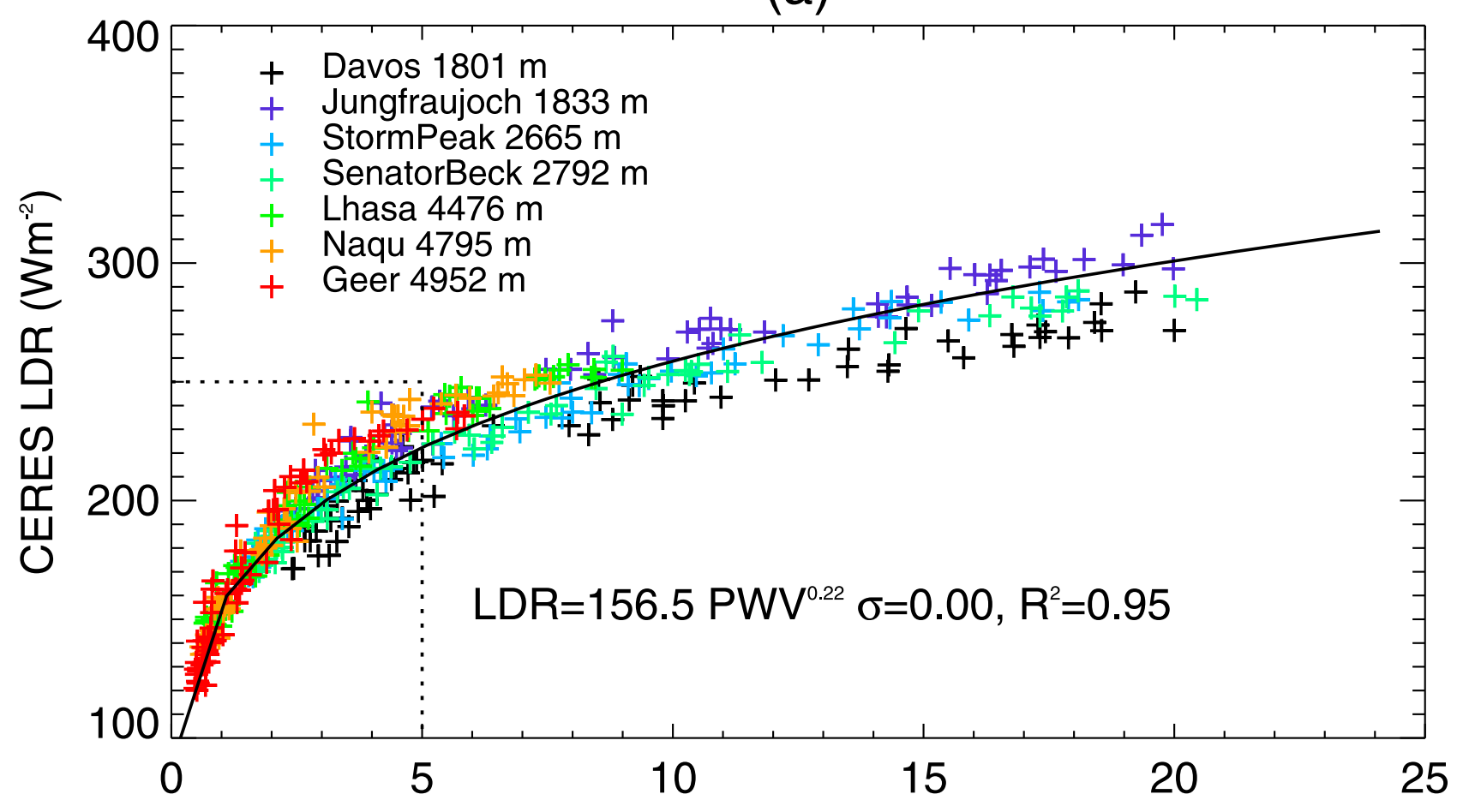

(b)

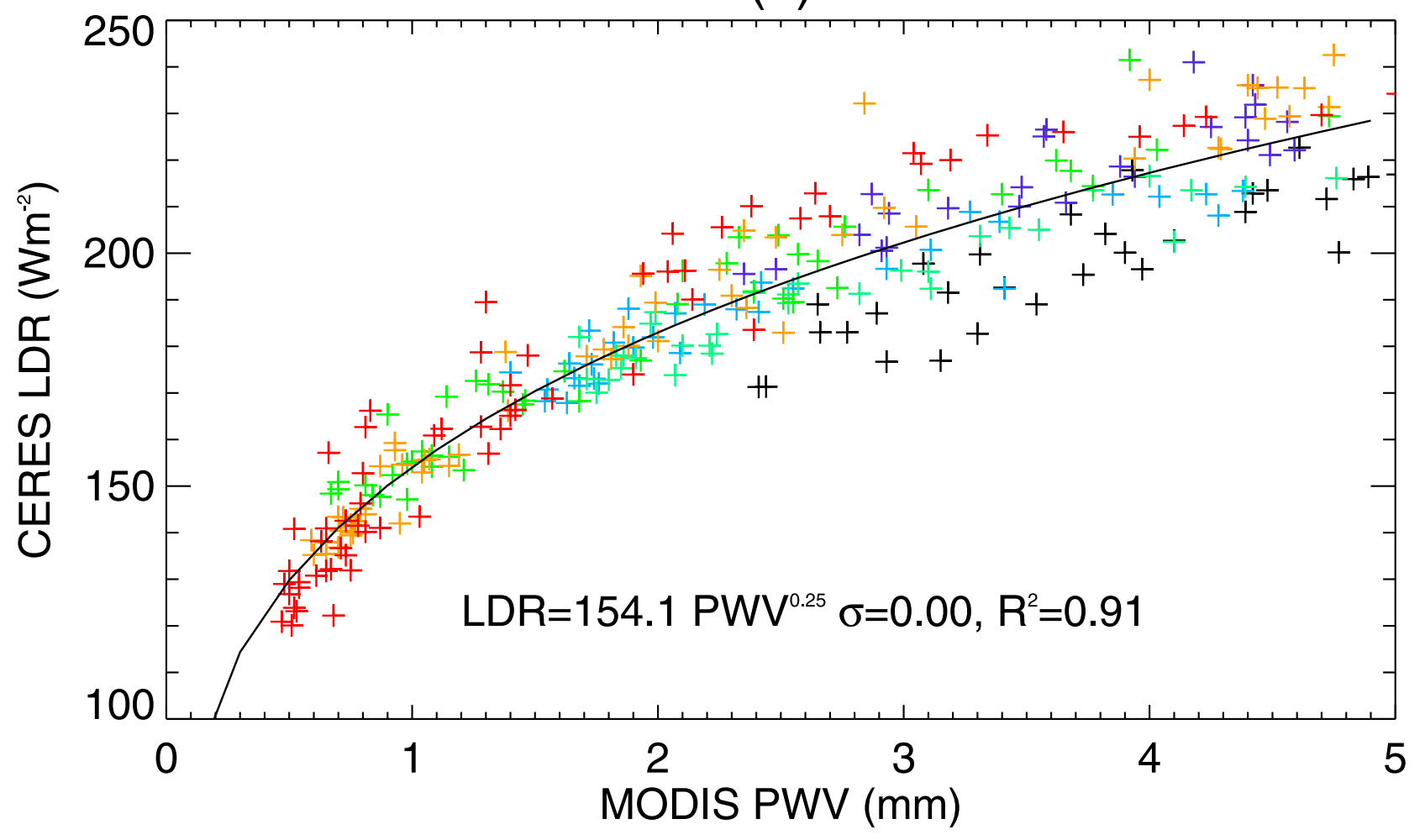

Figure 7. Monthly CERES longwave downward radiation versus MODIS PWV at seven high-elevation sites: the Alps (Davos, Jungfraujoch), the Rockies (Storm Peak, Senator Beck), and the Tibetan Plateau (Ge'er, Naqu, Lhasa). (a) For all retrievals from April 2000 to October 2005 and (b) same but for PWV $<5 \mathrm{~mm}$. The altitude of each site corresponds to the average altitude in the closest MODIS pixel and not to the actual instrumented site. 
errors in the instantaneous satellite retrievals, most likely owing to an inadequate cloud-clearing process, the monthly averaged results support our contention that satellite retrievals can be used to extend the observational database of atmospheric water vapor in high-elevation regions and that they can be used to examine potential water-vapor feedbacks in these otherwise data-sparse regions and thus provide a better understanding of climate variability in mountains.

[31] Acknowledgments. The Senator Beck Basin observations are provided by the Center for Snow and Avalanche Studies (http://www.snowstudies. org/). CERES data are provided by the Atmospheric Science Data Center at NASA Langley Research Center. MODIS MOD07/MYD07 files are provided by the Level 1 and Atmospheric Archive Distribution System at the NASA Goddard Space Flight Center. Weather station observations were obtained from the NCDC Climate Data Online archive at www7.ncdc.noaa.gov/CDO/cdo. This work is funded by the NSF grants 1064281 and 1064326, and partial support for JRM was provided by Project 32103 of the New Jersey Agricultural Experiment Station. We thank Imtiaz Rangwala for his help with the CSAS observations and manuscript and Yonghua Chen for helpful discussions. We are grateful to three anonymous reviewers for greatly improving this manuscript.

\section{References}

Ackerman S. A., K. I. Strabala, W. P. Menzel, R. A. Frey, C. C. Moeller, and L. E. Gumley (1998), Discriminating clear sky from clouds with MODIS, J. Geophys. Res., 103(D24), 32,141-32,157, doi: 10.1029/ 1998JD200032.

Ackerman, S. A., R. E. Holz, R. Frey, E. W. Eloranta, B. C. Maddux, and M. McGill (2008), Cloud detection with MODIS. Part II: Validation, J. Atmos. Oceanic Technol., 25, 1073-1086, doi:10.1175/ 2007JTECHA1053.1.

Adedokun, J. A. (1986), On a relationship for estimating precipitable water vapour aloft from surface humidity over West Africa, J. Climatol., 6, 161-172, doi:10.1002/joc.3370060205.

Adedokun, J. A. (1989), Surface humidity and precipitable water vapour linkage over West and Central Africa: Further clarification and evaluation of existing models, Int. J. Climatol., 9, 425-433, doi:10.1002/ joc. 3370090408 .

Beniston, M., and M. Rebetez (1996), Regional behavior of minimum temperatures in Switzerland for the period 1979-1993, Theor. Appl. Climatol., 53, 231-243, doi:10.1007/BF00871739.

Beniston, M., H. Diaz, and R. Bradley (1997), Climatic change at high elevation sites: An overview, Clim. Change, 36, 233-251, doi:10.1023/ A: 1005380714349

Bloom, S., et al. (2005), Documentation and validation of the Goddard Earth Observing System (GEOS) Data Assimilation System-Version 4, Tech. Rep. Ser. Global Model. Data Assim. 104606, 26 pp., NASA Goddard Space Flight Cent., Greenbelt, Md. [Available at http://www. gmao.gsfc.nasa.gov/systems/geos4/.]

Charlock, T. P., F. G. Rose, D. A. Rutan, T. L. Alberta, D. P. Kratz, L. H. Coleman, G. L. Smith, N. Manalo-Smith, and T. D. Bess (1997), Clouds and the Earth's Radiant Energy System (CERES) algorithm theoretical basis document: Compute surface and atmospheric fluxes (System 5.0), report, 84 pp., NASA Langley Res. Cent., Hampton, Va. [Available at http://asd-www.larc.nasa.gov/ATBD/.]

Charlock, T. P., F. G. Rose, D. A. Rutan, Z. Jin, and S. Kato (2006), The global surface and atmospheric radiation budget: An assessment of accuracy with 5 years of calculations and observations, paper presented at the 12th Conference on Atmospheric Radiation, Am. Meteorol. Soc., Madison, Wis., 10-14 July.

Chen, B., W. C. Chao, and X. Liu (2003), Enhanced climatic warming in the Tibetan Plateau due to doubling $\mathrm{CO}_{2}$ : A model study, Clim. Dyn., 20, 401-413.

Diaz, H., and R. Bradley (1997), Temperature variations during the last century at high elevation sites, Clim. Change, 36, 253-279, doi:10.1023/ A: 1005335731187 .

Fu, Q., and K.-N. Liou (1993), Parameterization of the radiative properties of cirrus clouds, J. Atmos. Sci., 50, 2008-2025, doi:10.1175/1520-0469 (1993)050<2008:POTRPO >2.0.CO;2.

Gautam, N., S. Basu, R. M. Gairola, and P. C. Pandey (1992), A curiosity regarding the relation between surface level humidity and precipitable water, Boundary Layer Meteorol., 60, 179-184, doi:10.1007/ BF00122067.
Giorgi, F., J. Hurrell, M. Marinucci, and M. Beniston (1997), Elevation dependency of the surface climate change signal: A model study, J. Clim., 10, 288-296, doi:10.1175/1520-0442(1997)010<0288:EDOTSC>2.0.CO;2.

Gupta, S. K., W. L. Darnell, and A. C. Wilber (1992), A parameterization for longwave surface radiation from satellite data: Recent improvements, J. Appl. Meteorol., 31, 1361-1367, doi:10.1175/1520-0450(1992) $031<1361$ :APFLSR $>2.0 . \mathrm{CO} ; 2$

Gupta, S. K., D. P. Kratz, P. W. Stackhouse Jr., C. Wilber, R. Zhang, and V. E. Sothcott (2010), Improvement of surface longwave flux algorithms used in CERES processing, J. Appl. Meteorol. Climatol., 49, 1579-1589, doi:10.1175/2010JAMC2463.1.

Inamdar, A. K., and V. Ramanathan (1997), On monitoring the atmospheric greenhouse effect from space, Tellus, 49b, 216-230.

Li, Z., J.-P. Muller, and P. Cross (2003), Comparison of precipitable water vapor derived from radiosonde, GPS, and moderate-resolution imaging spectroradiometer measurements, J. Geophys. Res., 108(D20), 4651, doi:10.1029/2003JD003372.

Liu, W. T. (1986), Statistical relation between monthly mean precipitable water and surface-level humidity over global oceans, Mon. Weather Rev., 114, 1591-1602, doi:10.1175/1520-0493(1986)114<1591:SRBMMP>2. $0 . \mathrm{CO} ; 2$.

Liu, X., and B. Chen (2000), Climatic warming in the Tibetan Plateau during recent decades, Int. J. Climatol., 20, 1729-1742, doi:10.1002/ 1097-0088(20001130)20:14<1729::AID-JOC556>3.0.CO;2-Y.

Mock, C. J., and K. W. Birkeland (2000), Snow avalanche climatology of the western United States mountain ranges, Bull. Am. Meteorol. Soc. $81,2367-2392$, doi:10.1175/1520-0477(2000)081<2367:SACOTW $>2$. 3.CO;2.

Pepin, N. C., and M. Losleben (2002), Climate change in the Colorado Rocky Mountains: Free air versus surface temperature trends, Int. J. Climatol., 22, 311-329, doi:10.1002/joc.740.

Philipona, R., B. Dürr, and C. Marty (2004), Greenhouse effect and altitude gradients over the Alps-by surface longwave radiation measurements and model calculated LOR, Theor. Appl. Climatol., 77, 1-7, doi:10.1007/ s00704-004-0038-7.

Qin, J., K. Yang, S. Liang, and X. Guo (2009), The altitudinal dependence of recent rapid warming over the Tibetan Plateau, Clim. Change, 97, 321-327, doi:10.1007/s10584-009-9733-9.

Rangwala, I., and J. R. Miller (2010), Twentieth century temperature trend in Colorado's San Juan Mountains, Arct. Antarct. Alp. Res., 42, 89-97, doi:10.1657/1938-4246-42.1.89.

Rangwala, I., J. R. Miller, and M. Xu (2009), Warming in the Tibetan Plateau: Possible influences of the changes in surface water vapor, Geophys. Res. Lett., 36, L06703, doi:10.1029/2009GL037245.

Rangwala, I., J. R. Miller, G. Russell, and M. Xu (2010), Using a global climate model to evaluate the influences of water vapor, snow cover and atmospheric aerosol on warming in the Tibetan Plateau during the twenty-first century, Clim. Dyn., 34, 859-872, doi:10.1007/s00382-009-0564-1.

Ruckstuhl, C., R. Philipona, J. Morland, and A. Ohmura (2007), Observed relationship between surface specific humidity, integrated water vapor, and longwave downward radiation at different altitudes, J. Geophys Res., 112, D03302, doi:10.1029/2006JD007850.

Salomonson, V. V., W. L. Barnes, P. W. Maymon, H. E. Montgomery, and H. Ostrow (1989), MODIS: Advanced facility instrument for studies of the earth as a system, IEEE Trans. Geosci. Remote Sens., 27, 145-153, doi:10.1109/36.20292.

Schmetz, J. (1989), Towards a surface radiation climatology: Retrieval of downward irradiances from satellites, Atmos. Res., 23, 287-321, doi:10.1016/0169-8095(89)90023-9.

Seemann, S. W., J. Li, W. P. Menzel, and L. E. Gumley (2003), Atmospheric temperature, moisture, and ozone from MODIS infrared radiances, J. Appl. Meteorol., 42, 1072-1091, doi:10.1175/1520-0450 (2003) $042<1072$ :OROATM $>2.0 . \mathrm{CO} ; 2$.

Seemann, S. W., E. E. Borbas, J. Li, W. P. Menzel, and L. E. Gumley (2006), MODIS atmospheric profile retrieval algorithm theoretical basis document, Coll. 5, 40 pp., NASA Goddard Space Flight Cent., Greenbelt, Md. [Available at http://modis-atmos.gsfc.nasa.gov/MOD07_L2/atbd. html.]

Smith, W. L. (1966), Note on the relationship between total precipitable water and surface dew point, J. Appl. Meteorol., 5, 726-727, doi:10.1175/1520-0450(1966)005<0726:NOTRBT >2.0.CO;2.

Wielicki, B., B. R. Barkstrom, E. F. Harrison, R. B. Lee III, G. L. Smith, and J. E. Cooper (1996), Clouds and the Earth's radiant energy system (CERES): An Earth observing system experiment, Bull. Am. Meteorol. Soc., 77, 853-868, doi:10.1175/1520-0477(1996)077<0853:CATERE $>2$. $0 . \mathrm{CO} ; 2$.

Yang, K., R. T. Pinker, Y. Ma, T. Koike, M. M. Wonsick, S. J. Cox, Y. Zhang, and P. Stackhouse (2008), Evaluation of satellite estimates of 
downward shortwave radiation over the Tibetan Plateau, J. Geophys. Res., 113, D17204, doi:10.1029/2007JD009736.

Zhang, Y.-C., W. B. Rossow, and P. W. Stackhouse Jr. (2006), Comparison of different global information sources used in surface radiative flux calculation: Radiative properties of the near-surface atmosphere, J. Geophys. Res., 111, D13106, doi:10.1029/2005JD006873.

Zhang, Y.-C., W. B. Rossow, and P. W. Stackhouse Jr. (2007), Comparison of different global information sources used in surface radiative flux calculation: Radiative properties of the surface, J. Geophys. Res., 112, D01102, doi:10.1029/2005JD007008.

C. Landry, Center for Snow and Avalanche Studies, PO Box 190, Silverton, CO 81433, USA.

J. R. Miller, Rutgers University, Marine and Coastal Sciences, 71 Dudley Rd., Rm. 111D, New Brunswick, NJ 08901, USA.

C. M. Naud, NASA GISS, Columbia University, 2880 Broadway, New York, NY 10025, USA. (cn2140@columbia.edu) 